\title{
The neuropsychology of variant CJD: a comparative study with inherited and sporadic forms of prion disease
}

\author{
R J Cordery, K Alner, L Cipolotti, M Ron, A Kennedy, J Collinge, M N Rossor
}

J Neurol Neurosurg Psychiatry 2005;76:330-336. doi: 10.1136/jnnp.2003.030320

See end of article for authors' affiliations

Correspondence to:

Correspondence to:
Professor Martin Rossor Dementia Research Group, The National Hospital for Neurology and Neurosurgery, Queen Square, London WCIN 3BG, UK; mrossor@ dementia.ion.ucl.ac.uk

Received 13 October 2003 In revised form 3 June 2004 Accepted 11 July 2004

\begin{abstract}
Objective: To assess cognitive function in variant Creutzfeldt-Jakob disease (VCJD). We describe the neuropsychological profiles of 10 cases and compare these data with cross sectional data obtained from patients with histologically confirmed sporadic CJD and cases with inherited prion disease with confirmed mutations in the prion protein gene.

Methods: Patients referred to the Specialist Cognitive Disorders Clinic at the National Hospital for Neurology and Neurosurgery and the National Prion Clinic at St Mary's Hospital, London for further investigation of suspected CJD were recruited into the study. The neuropsychological test battery evaluated general intelligence, visual and verbal memory, nominal skills, literacy skills, visual perception and visuospatial functions, and visuospatial and executive function.

Results: The results indicate that moderate to severe cognitive decline is a characteristic feature of $\mathrm{VCJD}$. Specifically, verbal and visual memory impairments and executive dysfunction were pervasive in all disease groups. Nominal skills were impaired in variant and sporadic CJD, significantly so when compared with the inherited prion disease group. Perceptual impairment was less frequent in the VCJD group than in the sporadic and inherited groups.

Conclusion: This study confirms the occurrence of generalised cognitive decline in patients with VCJD. Although decline in cognitive function ultimately affects all domains, there is a suggestion that some components of visual perception may be spared in VCJD. The results also suggest that nominal function may be preserved in some cases with inherited prion disease.
\end{abstract}

progression to akinetic mutism. ${ }^{1}$ Distinct strains or isolates of prions are recognised and these can be differentiated by biochemical differences in the protease-resistant $\operatorname{PrP}\left(\mathrm{PrP}^{\mathrm{Sc}}\right)$ present. A proportion of the marked phenotypic heterogeneity seen in sporadic CJD is likely to relate to the propagation of different prion strains. Molecular classifications of sporadic CJD have been proposed. ${ }^{6-8}$ Hill et al describe the presence of four types of $\mathrm{PrP}^{\mathrm{Sc}}$ (types 1-4) and a novel $\mathrm{PrP}^{\mathrm{Sc}}$, designated type 6 , in a single case of sporadic CJD. These $\mathrm{PrP}^{\mathrm{SC}}$ types are associated with a codon 129 status and duration of illness and neuropathological phenotypes have been described for each combination found. There are similarities in terms of neuropathology between type IMM, type $2 \mathrm{MM}$, type $3 \mathrm{VV}$, type $2 \mathrm{MV}$, and type $3 \mathrm{MV}$ groups, and types MM1, MM2 (cortical), VV2, MV1, and MV2 groups, respectively, from the previously published Parchi classification. $^{7}$

The clinical description of cases by Parchi et al gives details of the presence or absence of cognitive impairment during the illness course. The authors state that dementia characterised all subjects with the exception of a relatively small group of MMI and MVI patients who abruptly lapsed into stupor or coma after showing neurological signs without dementia at onset. For all other groups, dementia is a feature of the illness. This cognitive impairment has been described as invariably present at onset in the VVl and MM2-C subtypes. In contrast, it appears to occur later in the VV2 subtype (in this group only $27 \%$ of cases had cognitive

Abbreviations: BSE, bovine spongiform encephalopathy; CJD, Creutzfeldt-Jakob disease; FFI, familial fatal insomnia; FIQ, full IQ; GSS, Gerstmann-Sträussler-Scheinker disease; $I Q$, intelligence quotient; NART, National Adult Reading Test; PIQ, performance IQ; vCJD, variant Creutzfeldt-Jakob disease; VIQ, verbal IQ; WAIS-R, Wechsler Adult Intelligence Scale-Revised dementia, occurring usually in the age range 45-75 years, with a short course of weeks to months, and usually 
impairment at the onset of the illness). The MM2-T subgroup is indistinguishable from the thalamic form of CJD and FFI. ${ }^{9}{ }^{10}$ FFI is characterised by a picture of cognitive decline, with fluctuations in attention and vigilance levels, associated with disturbances of memory and temporal organisation, and may also occur on a sporadic basis. ${ }^{11}$

In inherited prion disease, at least 20 pathogenic mutations in the prion gene, all autosomal dominantly inherited, have been detailed.' Kindreds have been described with phenotypes encompassing familial CJD and GSS. There is often marked phenotypic variability even within one family. ${ }^{12}$

The suggestion of distinct neuropsychological profiles associated with CJD has been proposed in the recent publication of a series of case reports and associated neuropsychology records from six patients with CJD (four sporadic and two familial cases). ${ }^{13}$ Three of the patients with sporadic CJD had focal cortical deficits, one had visual impairment leading to cortical blindness, and two had language impairment (one case had anomia and the other writing and spelling difficulties). All six cases had variable responsiveness, made intrusion errors, and showed profound motor and verbal perseveration.

Acquired prion disease can occur when infectious material is inoculated centrally in the nervous system, for example following corneal transplantation, dura mater grafting, or from inadequately sterilised neurosurgical instruments. ${ }^{14}{ }^{15} \mathrm{In}$ these cases the ensuing illness generally resembles sporadic CJD with rapid dementia. Other acquired forms of CJD, following the peripheral administration of human cadaveric pituitary derived growth hormone or gonadotrophin, have a predominantly cerebellar onset. ${ }^{16} \mathrm{~A}$ significant decline in general intelligence (intelligence quotient, IQ) is detectable at an early stage and becomes more prominent as the illness progresses. ${ }^{17} 18$ In Papua New Guinea oral exposure to humans with prions via ritualistic cannibalism is the basis of Kuru. In this disease dementia is much less apparent, although in the terminal stages the patient's faculties are often obtunded. ${ }^{19}$

Pronounced cognitive decline is also central to vCJD. It is possible that analysis of its features may aid its differential diagnosis from other forms of prion diseases and other neuropsychiatric conditions. More information is emerging regarding the neuropsychological profile and therefore the distinguishing features of VCJD and the stage in the illness at which these occur. Until recently, only qualitative and anecdotal accounts of the cognitive decline had been reported. Two of the first published cases of vCJD presented with symptoms of forgetfulness and intermittent confusion from the onset of the illness, associated with significant deterioration in cognition. Bateman and colleagues ${ }^{20}$ described an 18 year old male who complained he had "gone nutty". He complained of a reduction in short term memory and was disoriented as to person, time, and place. Tabrizi et $a^{l^{21}}$ described a 28 year old female presenting with increasing forgetfulness, confusion, and a reduced short term memory. A report of 14 cases of variant $\mathrm{CJD}^{22}$ revealed a rapid progression to global cognitive impairment. Fluctuations in individuals' performance over hours or days were noted. Three further cases with significant cognitive impairment were reported from Leicestershire in the UK. ${ }^{23}$ In particular, one patient (patient 1) showed impairments of memory, verbal fluency, spatial judgement, and language, another patient (patient 2) showed severe behavioural change, characterised by emotional lability and aggressiveness, and a third (patient 3 ) showed significant cognitive decline characterised by memory impairment and personality change. A review of the first 35 cases of variant $\mathrm{CJD}^{4}$ indicated that six out of 35 had early symptomatic cognitive impairment, and all progressed to a dementia syndrome later in the illness. In 10 patients, neuropsychological assessment was carried out after the development of neurological symptoms. For all patients significant cognitive impairment has been reported. The most recent retrospective case note review of the first 100 cases confirmed that the early stages are dominated by psychiatric symptoms, but that in many cases the possibility of an underlying disorder was only raised with the development of cognitive impairment. Cognitive decline developed after a median of 4-7.5 months and included impairment of memory and concentration, disorientation, or confusion. The authors note that this was present in a minority of cases from the earliest stage. ${ }^{24}$

Detailed quantitative neuropsychological data have been reported in a previous case study. ${ }^{25}$ This single case study reports intellectual decline, severe memory impairment, and executive dysfunction. Some longitudinal data are included in the study showing a progressive decline over a 4 month period.

More details regarding the neuropsychology profile of vCJD are now available from a retrospective study of 24 cases. The pattern reported is one of combined cortical and subcortical dementia with prominent impairment, particularly on tests of memory, executive function, speed, and attention, and visuoperceptual reasoning. ${ }^{26}$

To assess further cognitive function in VCJD, we describe the detailed neuropsychology profiles of 10 cases. We compare these data with cross sectional data obtained from patients with histologically confirmed sporadic CJD and cases with inherited prion disease with confirmed mutations in the prion protein gene. Recognition of distinguishing features in the neuropsychology profiles may aid the clinical differentiation of these conditions.

\section{EXPERIMENTAL INVESTIGATIONS}

\section{Patient groups}

Patients referred to the Specialist Cognitive Disorders Clinic at the National Hospital for Neurology and Neurosurgery and the National Prion Clinic at St Mary's Hospital, London with suspected vCJD were recruited into a study to assess the early diagnostic features of the disease. Neuropsychology assessments from 12 cases with definite or probable vCJD according to disease classification criteria (Department of Health, February 2003) were compared to data from a control group. These 12 patients were the only ones well enough to attempt formal testing out of 15 cases of definite or probable vCJD seen during the 4 year study period. Patients referred to these centres with other forms of prion disease were recruited into the control group which comprised 10 patients with sporadic and 18 cases with familial forms of the disease.

The mean age and sex distribution of each patient group are shown in table 1.

\section{Neuropsychological evaluation}

Patients were assessed in the Neuropsychology Department of the National Hospital for Neurology and Neurosurgery. MRI scans were carried out at approximately the same time. The neuropsychological battery included tests evaluating: i) general intelligence (Wechsler Adult Intelligence ScaleRevised, WAIS- $\mathrm{R}^{27}$ (seven subsets of the WAIS-R were considered: vocabulary, digit span, arithmetic, similarities, picture completion, picture arrangement, and block design) and Coloured Progressive Matrices ${ }^{28}$ ); ii) visual and verbal memory (Recognition Memory Test, $\mathrm{RMT}^{29}$ ); iii) nominal skills (Graded Difficulty Naming Test, GNT ${ }^{30}$ and the Oldfield Picture Naming Test, Oldfield ${ }^{31}$ ); iv) literacy skills (National Adult Reading Test (NART). ${ }^{32}$ The NART not only provides a measure of reading skills but also an estimate (reading IQ equivalent) of premorbid optimal level of functioning); v) visual perception and visuospatial functions (Incomplete 
Table 1 Mean age and sex distribution by disease group

\begin{tabular}{|c|c|c|c|c|c|c|c|c|c|}
\hline & \multicolumn{3}{|c|}{ Variant CJD } & \multicolumn{3}{|c|}{ Sporadic CJD } & \multicolumn{3}{|c|}{ Inherited prion disease } \\
\hline & $\mathbf{n}$ & $\begin{array}{l}\text { Mean age } \\
\text { (years) }\end{array}$ & SD & $\mathbf{n}$ & $\begin{array}{l}\text { Mean age } \\
\text { (years) }\end{array}$ & SD & $\mathbf{n}$ & $\begin{array}{l}\text { Mean age } \\
\text { (years) }\end{array}$ & SD \\
\hline Males & 5 & 28 & 7.3 & 8 & 55 & 8.7 & 12 & 42 & 10.0 \\
\hline Females & 7 & 23 & 4.6 & 2 & 56 & 6.0 & 6 & 40 & 4.2 \\
\hline Total & 12 & 25 & 6.3 & 10 & 55 & 8.7 & 18 & 42 & 9.0 \\
\hline
\end{tabular}

Letters, IL; Object Decision, OD; Dot Counting, DC; Cube Analysis, CA; and Position Discrimination, $\left.\mathrm{PD}^{33}\right)$; vi) and executive functions (Wisconsin Card Sorting test, WCST ${ }^{34}$ and the Weigl Sorting Test ${ }^{35}$ ).

Derived scores were calculated for each cognitive domain for each patient including a verbal IQ (VIQ), performance IQ (PIQ), and a full IQ (FIQ). The NART provided not only a measure of reading skills but also an estimate of the premorbid optimal level of functioning. The intellectual functioning score was the difference between the NART expected IQ values and the observed IQ values. A difference of 10 was taken as evidence of mild intellectual decline, a difference of between 11 and 20 was taken as evidence of moderate intellectual decline, and a difference of greater than 20 was taken as evidence of severe intellectual decline. Two individuals presented with acquired dyslexia so the NART was not used to estimate their premorbid intellectual functioning. In these cases the education and occupational background of the individuals was used to provide an estimate of premorbid ability. Test scores for memory, naming, and perceptual function are difficult to interpret in isolation. The memory and naming scores were derived by converting the standardised test performance into percentile scores, referencing existing normative data. Scores at or below the 5 th percentile were taken to indicate a memory or naming impairment. Perceptual scores were derived by converting the standardised test performance scores into cut off points. Scores at or below the $5 \%$ cut off were taken to indicate a perceptual impairment. The frontal executive scores were derived according to standardised procedures for the WCST. For the Weigl sorting test, patient performance was simply classed as unimpaired if the subject was able to reach both solutions or impaired if the subject could reach only one or neither of the two correct solutions.

As the NART was not used as an estimate of premorbid intellectual function in some cases, it was not possible to apply a statistical method to compare the degree of intellectual decline between the three disease groups. However, the proportions of patients presenting with deficits in each of the five cognitive domains (verbal and visual memory, naming, visuoperception, and frontal executive function) were compared using a $3 \times 2$ Fisher's exact test (as three comparisons were being made, variant $v$ sporadic, variant $v$ familial and sporadic $v$ familial). One value in the $3 \times 2$ table was significant and so three different $2 \times 2$ Fisher's exact tests were then carried out relating to each of the three comparisons above, to determine where the difference lay.

\section{RESULTS}

Patients with vCJD were significantly younger than the two other patient groups. There was a preponderance of males in the sporadic CJD and inherited prion disease groups. The mean duration of illness at the time of first neuropsychology assessment was 12.4 months (range 9-25, median 10 months, $\mathrm{n}=12$ ) in the variant group, 41.7 months (range 1-132, median 24 months, $\mathrm{n}=18$ ) in the inherited group, and 7.7 months (range $1-15$, median 7 months, $\mathrm{n}=10$ ) in the sporadic group. The sporadic cases were noted to have a young mean age at onset and long illness duration. None of the sporadic cases were thought to have the Heidenhain variant of CJD.

The clinical characteristics and imaging and electroencephalogram findings for all cases are summarised in table 2 .

At the time of assessment (prior to tonsillar biopsy) nine cases were classified as probable and three as possible vCJD. Since then, seven cases have been confirmed as definite with post mortem histology and five remain probable. Tonsil biopsy was positive in all cases. All inherited cases had a confirmed mutation in PRNP and symptoms attributable to the disease. There is histological confirmation of disease for all 10 sporadic cases, eight from post mortem examination and two from brain biopsy.

\section{Neuropsychological results}

Ten patients could not be formally assessed as they were unable to cope with the test demands (two in the variant CJD group, six in the sporadic CJD group, and two in the inherited prion disease group). Eight patients with symptomatic inherited prion disease were assessed on more than one occasion using the same test battery, with a mean difference of 8.8 months between assessments.

The cognitive deficits in the three patient groups are shown in table 3. A significant intellectual impairment was present in all three patient groups. In the vCJD group the majority of the patients presented with a severe VIQ and PIQ impairment. Only three patients presented with either a mild or moderate VIQ impairment. Similarly the sporadic CJD group showed severe intellectual decline with only one notable exception. A severe intellectual decline was also present in the majority of the inherited prion disease cases. However, in this group four patients showed only a mild or a moderate VIQ or PIQ decline and two patients were unimpaired (F4 and F13; table 2).

The patients' performances in each of the five cognitive domains tested (memory for words and faces, nominal, perceptual, and executive functions) are shown in table 4 . Memory functions (words and faces) were impaired in all the variant CJD patients. In the sporadic group, all patients with one exception presented with a memory impairment for words and faces. The patient with normal memory also showed intact intellectual functions. In the inherited prion disease group, the incidence of memory impairment was also high. Only five patients showed either selective modality specific memory impairment or no impairment.

Nominal skills were severely impaired in nearly all patients with variant and sporadic CJD with only one exception in each group. By contrast, only a minority of patients with inherited prion disease presented with a nominal impairment and all of these had verbal and visual memory impairment. This difference in the proportion of cases with nominal impairment was statistically significant compared across the disease groups $(p=0.006)$. Three further pairwise comparisons showed that the difference lay between variant and familial groups. The proportion of patients with nominal 


\begin{tabular}{|c|c|c|c|c|c|c|c|c|c|c|c|c|c|}
\hline & $\begin{array}{l}\text { PRNP } \\
\text { mutation }\end{array}$ & $\begin{array}{l}\text { Personality } \\
\text { change/ } \\
\text { depression }\end{array}$ & $\begin{array}{l}\text { Cognitive } \\
\text { decline }\end{array}$ & $\begin{array}{l}\text { Sensory } \\
\text { symptoms }\end{array}$ & $\begin{array}{l}\text { Chorea- } \\
\text { dystonia }\end{array}$ & $\begin{array}{l}\text { Myo- } \\
\text { clonus }\end{array}$ & Ataxia & $\begin{array}{l}\text { Pyra- } \\
\text { midal }\end{array}$ & $\begin{array}{l}\text { Extra- } \\
\text { pyramidal }\end{array}$ & $\begin{array}{l}\text { MR } \\
\text { atrophy }\end{array}$ & $\begin{array}{l}\text { MRI } \\
\text { signal } \\
\text { change }\end{array}$ & $\begin{array}{l}\text { EEG } \\
\text { periodic } \\
\text { com- } \\
\text { plexes }\end{array}$ & $\begin{array}{l}\text { EEG non- } \\
\text { specific } \\
\text { abnor- } \\
\text { malities }\end{array}$ \\
\hline $\mathrm{V} 1$ & - & + & + & + & + & - & + & + & - & - & Thalamus & - & + \\
\hline V2 & - & + & + & + & + & - & + & - & - & - & Thalamus & - & + \\
\hline V3 & - & + & + & + & + & + & + & + & - & - & Thalamus & - & + \\
\hline V4 & - & + & + & - & + & + & - & + & - & - & Thalamus & - & + \\
\hline V5 & - & + & + & + & + & - & + & + & - & - & Thalamus & - & + \\
\hline V6 & - & + & + & - & + & - & + & - & - & - & Thalamus & - & + \\
\hline V7 & - & + & + & + & - & - & + & + & - & - & Thalamus & - & + \\
\hline V8 & - & + & + & + & + & + & + & + & - & - & Thalamus & - & + \\
\hline V9 & - & - & + & - & + & + & + & + & - & - & Thalamus & - & - \\
\hline V10 & - & + & + & + & + & - & + & + & - & - & $\begin{array}{l}\text { Occipital } \\
\text { white }\end{array}$ & - & + \\
\hline V11 & - & + & + & - & + & + & + & + & - & - & - & - & + \\
\hline V12 & - & + & + & - & - & - & - & + & - & - & - & - & + \\
\hline $\mathrm{Fl}$ & 144 & - & + & - & - & - & + & - & + & + & - & - & + \\
\hline F2 & P102L & + & + & NA & NA & - & + & + & - & - & - & - & + \\
\hline F3 & P102L & + & + & - & - & - & + & + & - & + & - & - & + \\
\hline F4 & Al17V & - & + & - & - & + & + & + & + & + & - & NT & NT \\
\hline F5 & Al17V & + & + & - & - & - & + & - & - & + & $\begin{array}{l}\text { White } \\
\text { matter }\end{array}$ & - & + \\
\hline F6 & E200K & + & + & - & - & + & + & + & - & + & - & - & + \\
\hline F7 & E200K & - & - & - & + & + & + & - & - & - & - & - & + \\
\hline F8 & 144 & + & + & NA & NA & - & + & - & + & + & - & - & + \\
\hline F9 & Novel $^{*}$ & + & + & + & - & - & + & + & - & - & $\begin{array}{l}\text { Mesial } \\
\text { frontal }\end{array}$ & - & + \\
\hline F10 & 144 & + & + & NA & NA & + & + & - & - & + & - & - & + \\
\hline $\mathrm{F} 11$ & 144 & + & + & - & - & - & + & - & - & + & - & - & + \\
\hline $\mathrm{F} 12$ & 144 & - & + & - & - & + & + & - & + & + & - & - & + \\
\hline $\mathrm{F} 13$ & 144 & + & + & - & - & - & + & - & - & + & - & - & + \\
\hline $\mathrm{F} 14$ & 144 & + & + & - & - & - & - & - & - & + & - & - & + \\
\hline F15 & 144 & - & + & - & - & - & + & - & - & + & - & - & + \\
\hline F16 & 144 & + & + & - & - & + & + & - & + & + & - & NA & NA \\
\hline F17 & 144 & + & + & - & - & - & + & - & - & + & - & - & - \\
\hline F18 & 144 & - & + & - & - & - & - & - & - & + & - & - & + \\
\hline S1 & - & - & + & - & + & + & + & - & - & - & - & - & + \\
\hline S2 & - & + & + & - & + & - & - & + & + & NA & NA & NA & NA \\
\hline S3 & - & + & + & - & - & + & - & + & + & - & Cortical & + & - \\
\hline S4 & - & - & + & - & - & - & - & - & - & + & - & - & + \\
\hline S5 & - & + & + & - & - & + & + & - & - & + & - & NA & NA \\
\hline S6 & - & - & + & - & - & - & + & - & + & - & - & - & + \\
\hline S7 & - & + & + & - & - & + & + & + & - & - & $\begin{array}{l}\text { Caudate, } \\
\text { lentiform }\end{array}$ & - & + \\
\hline S8 & - & + & + & - & - & - & - & - & - & - & - & NA & NA \\
\hline S9 & - & + & + & + & + & + & - & + & + & - & - & + & - \\
\hline s10 & - & - & + & - & + & + & + & + & - & NT & NT & - & - \\
\hline
\end{tabular}

impairment was statistically significantly different in the variant and familial groups $(\mathrm{p}=0.005)$.

Perceptual impairment was less common in patients with vCJD than in the other groups. Only two patients were found impaired and both had severe, global cognitive decline. By contrast, half the sporadic CJD and inherited prion disease patients presented with perceptual impairment. This difference in the proportion of cases in each disease group with perceptual impairment was not statistically significant $(\mathrm{p}=0.31)$.

Frontal executive impairment was pervasive in all three patient groups and only two patients with inherited prion disease were unimpaired.

The longitudinal data available for the eight cases with inherited prion disease are presented in table $5 \mathrm{a}$ and $\mathrm{b}$. All cases with intellectual decline at the first assessment showed evidence of progression at follow up. One individual, with no intellectual decline initially, remained unchanged l year later. Similarly, all eight patients with impairment in one of the five cognitive domains at initial assessment also showed further progression on subsequent testing.

The duration of total illness was known for a subgroup of patients in each of the disease groups and this allowed an estimation of the stage at which testing was performed. In the CJD group $(n=10)$, the assessments took place at a mean of $85 \%$ of the way through the illness (range $71-93 \%$ ). In the sporadic group $(n=5)$, the assessments took place at a mean of 55\% through the illness (range 44-67\%). The illness duration varied widely (with many years difference) in the familial group and so it was not possible to estimate when testing had been performed.

\section{Neuropathological findings}

Post mortem histological examination of brain tissue was performed in five of the variant CJD cases in this study. The disease had advanced significantly in all cases prior to death and so the pattern of histology would not directly reflect that at the time of testing. All five cases showed severe spongiform change, neuronal loss, and astrogliosis in the basal ganglia and thalamus. These changes and florid plaques were seen to a lesser extent throughout the cerebral cortex, most severely in the occipital cortex. Widespread prion protein deposition was demonstrated by immunohistochemistry. In three cases the cerebellum was noted to be severely affected (Vl, V4, and V7). In one case where the hippocampus was studied, it was relatively spared (V9). 
Table 3 Level of intellectual decline by patient group

\begin{tabular}{llll}
\hline & $\begin{array}{l}\text { Variant CJD, } \\
\mathbf{n}=10\end{array}$ & $\begin{array}{l}\text { Sporadic } \\
\text { CJD, } \mathbf{n = 4}\end{array}$ & $\begin{array}{l}\text { Inherited } \\
\text { prion disease, } \\
\mathbf{n}=16\end{array}$ \\
\hline VIQ & - & 1 & 2 \\
None & 1 & - & 1 \\
Mild decline & 2 & - & 3 \\
Moderate decline & 7 & 3 & 10 \\
Severe decline & 7 & 1 & 1 \\
PIQ & - & - & - \\
None & - & - & 2 \\
Mild decline & - & 3 & 13 \\
Moderate decline & 10 & 1 & 1 \\
$\quad$ Severe decline & - & - & - \\
FIQ & - & - & 13 \\
$\quad$ None & - & 3 & \\
Mild decline & - & & \\
Moderate decline & - & & \\
Severe decline & 10 &
\end{tabular}

\section{DISCUSSION}

The neuropsychological results indicate that moderate and severe intellectual decline is a characteristic feature of variant CJD with only a few notable exceptions. This is also true for sporadic CJD, but inherited prion disease patients are generally less severely impaired at early stages of an illness with a longer time course. It should be noted that only four of the sporadic CJD group cases were evaluated as the remainder were more severely impaired and unable to undergo testing.

The presence of cognitive impairment was common in all patient groups. Specifically, memory impairments for words and faces and frontal executive impairments were pervasive in all patient groups. Nominal skills were similarly impaired in patients with variant and sporadic CJD. However, there was a statistically significant difference in the proportion of cases with nominal impairment in these groups compared to the proportion in the inherited prion disease group.

In the vCJD group only a minority of patients presented with a perceptual impairment compared with half the patients in the sporadic CJD and inherited prion disease groups. However, this difference in the proportions of cases with perceptual impairment in these groups was not statistically significant.

Clinically the diseases differ mainly in the speed of their progression and this is reflected in the cognitive profiles of the groups. This is also a limitation of the study in that it is difficult to match patients at comparable stages or severity of disease. The time course of inherited prion disease differs with each type of mutation in PRNP, and between patients in the same kindred, but is usually significantly longer than that found in sporadic CJD. Some mutations are associated with longstanding personality disorders which manifest long before other neurological symptoms and signs develop. ${ }^{12}$ The longitudinal data provide further characterisation of the longer time course of inherited prion disease. Cases with sporadic CJD characteristically have a rapidly progressive dementia syndrome. Six out of 10 of the sporadic cases in our study were already untestable at the time of referral to the National Hospital.

Patients with vCJD also show rapid cognitive decline. At the time of initial assessment (at a mean of 12.4 months from illness onset) the majority of the variant CJD cases had developed a profile of moderate to severe intellectual impairment, memory and nominal impairment, and frontal executive dysfunction with, in many cases, sparing of visuoperceptual function. This was at a relatively late stage
Table 4 Number of patients impaired per group (compared using Fisher's exact test)

\begin{tabular}{lccll}
\hline & $\begin{array}{l}\text { Variant } \\
\text { CJD, } \\
\mathbf{n}=10\end{array}$ & $\begin{array}{l}\text { Sporadic } \\
\text { CJD, } \\
\mathbf{n}=\mathbf{4}\end{array}$ & $\begin{array}{l}\text { Inherited } \\
\text { prion disease, } \\
\mathbf{n}=16\end{array}$ & $\begin{array}{l}\mathbf{p} \\
\text { Value }\end{array}$ \\
\hline $\begin{array}{l}\text { Memory } \\
\text { (words) }\end{array}$ & 10 & 3 & 11 & 0.13 \\
$\begin{array}{l}\text { Memory } \\
\text { (faces) }\end{array}$ & 10 & 3 & 13 & 0.32 \\
$\begin{array}{l}\text { Nominal } \\
\text { skills* }\end{array}$ & 9 & 3 & 5 & 0.006 \\
$\begin{array}{l}\text { Visual } \\
\text { perceptiont }\end{array}$ & 2 & 2 & 8 & 0.31 \\
Executive & $9 \ddagger$ & $3 \S$ & 14 & 0.24 \\
\hline
\end{tabular}

Standardised test performances converted to percentile scores or cut off points: ${ }^{*} \leqslant 5$ th percentile indicating memory and naming impairment; $\dagger \leqslant 5 \%$ cut off indicating perceptual impairment.

$\ddagger$ Only nine variant CJD patients tested; Sonly three sporadic CJD patients tested.

Table 5 Longitudinal data for cases with inherited prion disease* $^{*}$

\begin{tabular}{|c|c|c|}
\hline & First assessment & Second assessment \\
\hline \multicolumn{3}{|c|}{ A. Level of intellectual decline in the inherited prion disease group } \\
\hline \multicolumn{3}{|l|}{$\mathrm{VIQ}$} \\
\hline None & 2 & 1 \\
\hline Mild decline & 1 & - \\
\hline Moderate decline & 1 & 3 \\
\hline Severe decline & 4 & 4 \\
\hline \multicolumn{3}{|l|}{$\mathrm{PIQ}$} \\
\hline None & 1 & 1 \\
\hline Mild decline & - & - \\
\hline Moderate decline & 2 & 2 \\
\hline Severe decline & 5 & 5 \\
\hline \multicolumn{3}{|l|}{$\mathrm{FIQ}$} \\
\hline None & 1 & 1 \\
\hline Mild decline & - & - \\
\hline Moderate decline & 2 & 2 \\
\hline Severe decline & 5 & 5 \\
\hline \multicolumn{3}{|c|}{ B. Number of impaired cases with inherited prion disease } \\
\hline Memory (words) & 4 & 6 \\
\hline Memory (faces) & 6 & 7 \\
\hline Nominal skills & 3 & 4 \\
\hline Visual perception & 4 & 4 \\
\hline Frontal & 7 & 8 \\
\hline
\end{tabular}

in the illness course when there were also overt neurological signs. However, our experience of a further case, not part of this study, shows that this profile may be seen as early as 3 months from symptom onset.

One case presenting at an early stage in the illness, that is, after only 2 months of symptoms, has been reported in detail in the literature. ${ }^{25}$ This patient performed below average on tests of intellectual functioning (WAIS-R). He also showed impairment in verbal reasoning, naming, and verbal fluency. However, he performed well on a face perception test. The authors noted the widespread distribution of spongiform change at autopsy, greatest in the caudate and putamen. There was also marked neuronal loss and astrogliosis in these nuclei and in the dorsal and posterior thalamus and occipital cortex. Florid plaques were widely distributed. The authors suggest that primary subcortical damage (of the thalamus and neostriatum) with secondary frontal lobe dysfunction may account for the pattern of generalised cognitive impairment. 
The histological features of VCJD which distinguish it from the other forms of prion disease include spongiform change which is most pronounced in the basal ganglia, marked thalamic gliosis, and pronounced PrP deposition in the occipital cortex and the molecular layer of the cerebellum (perineuronal and perivascular deposits). ${ }^{36}$ This pattern of histological change was demonstrated in our cases with the basal ganglia and thalamus showing severe spongiform change, neuronal loss, and astrogliosis. These changes and florid plaques were seen to a lesser extent throughout the cerebral cortex (most severely in the occipital cortex). Widespread prion protein deposition was demonstrated by immunohistochemistry (including in the cerebellum).

From the available histology at the end stage of the disease, it is not possible to distinguish the origin of the cognitive impairment, which may primarily occur as a result of cortical damage or through thalamic and basal ganglia degeneration. The dementia syndrome of FFI has been correlated with lesions in the anteroventral and medialdorsal thalamic nuclei $^{10}$ and one of the characteristic features of variant CJD is the prominent reactive astrogliosis seen in the thalamus (pulvinar region). This is thought to account for the high signal seen on T2 and proton density MR images in the pulvinar region in these cases, called the pulvinar sign. ${ }^{37}$ The pulvinar is a large region of the thalamus overlying the rostrolateral extent of the midbrain. This region is thought to serve one of the many functions involved in the visual system to generate visual perception. Computation of a scene by the visual system must be performed with speed and in great detail but with allowance for spatial constancy. ${ }^{38}$ Some images in a scene are conspicuous and it is thought that one of the roles of the pulvinar is to indicate the salience of visual images and events. The retina projects to the contralateral pulvinar, which in turn has projections to the visual cortex and the association areas of the frontal and parietal cortices.

A contributory role for the thalamus has also been suggested following pathological analysis of the three sporadic and one familial case described by Snowden et al. ${ }^{13}$ The authors propose functional disruption of basal gangliathalamo-cortical circuitry as a mechanism for neuropsychology deficits. In the review of 24 cases by Kapur et al, approximately $50 \%$ of cases were shown to have significant impairment on the incomplete letters test of the Visual Object and Space Perception (VOSP) battery (after an estimated 59\% of total illness duration) ${ }^{26}$ In our group of vCJD patients, the scores for visual perception appeared to be preserved until a later stage in the illness. However the tests performed were relatively simple and further examination of the patients' ability to determine the context of scenes and the relevance of images would be of value, as these skills have been shown to be lacking in a patient with pulvinar damage. ${ }^{38}$ Further investigation should include detailed examination of visual perception.

In conclusion, this study confirms the occurrence of generalised intellectual decline in patients with variant CJD and further demonstrates that this may occur at an early stage in the illness course. There is a suggestion that although decline in cognitive function ultimately affects all domains, some components of visual perception may be spared by the pathological processes of variant CJD. It is also proposed that nominal function may be preserved in some cases with inherited prion disease.

\section{Authors' affiliations}

R J Cordery, M N Rossor, Dementia Research Group, Department of Neurodegenerative Disease, Institute of Neurology, University College London, London, UK
R J Cordery, M N Rossor, Division of Neuroscience and Psychological Medicine, Faculty of Medicine, Imperial College of Science, Technology and Medicine, London, UK

K Alner, L Cipolotti, Department of Neuropsychology, The National Hospital for Neurology and Neurosurgery, London, UK

M Ron, Department of Neuropsychiatry, Institute of Neurology,

University College London, London, UK

A Kennedy, J Collinge, MRC Prion Unit, Department of

Neurodegenerative Diseases, Institute of Neurology, University College London, London, UK

A Kennedy, J Collinge, National Prion Clinic, St Mary's Hospital London, London, UK

This study formed part of project funded by a grant from the Medical Research Council of Great Britain.

Competing interests: none declared

Martin Rossor assumed editorship of the Journal of Neurology, Neurosurgery and Psychiatry after submission of this manuscript and has had no involvement in the review process

\section{REFERENCES}

1 Collinge J. Prion diseases of humans and animals: their causes and molecular basis. Annu Rev Neurosci 2001 ;24:519-50.

2 Hill AF, Desbruslais $M$, Joiner $S$, et al. The same prion strain causes VCJD and BSE. Nature 1997;389:448-50.

3 Bruce ME, Will RG, Ironside JW, et al. Transmissions to mice indicate that "new variant" CJD is caused by BSE. Nature 1997;389:498-501.

4 Will RG, Zeidler M, Stewart GE, et al. Diagnosis of new variant CreutzfeldtJakob disease. Ann Neurol 2000;47:575-82.

5 Asante EA, Linehan JM, Desbruslais $M$, et al. BSE prions propagate as either variant CJD-like or sporadic CJD-like strains in transgenic mice expressing human prion protein. EMBO J 2002;21(23):6358-66.

6 Collinge J, Sidle KCL, Meads J, et al. Molecular analysis of prion strain variation and the aetiology of "new variant" CJD. Nature 1996;383:685-90.

7 Parchi P, Giese A, Capellari S, et al. Classification of sporadic CreutzfeldtJakob disease based on molecular and phenotypic analysis of 300 subjects. Ann Neurol 1999;46:224-33.

8 Hill AF, Joiner S, Wadsworth JDF, et al. Molecular classification of sporadic Creutzfeldt-Jakob disease. Brain 2003;126:1333-46.

9 Kawasaki K, Wakabayashi K, Kawakami A, et al. Thalamic form of Creutzfeldt-Jakob disease or fatal insomnia? Report of a sporadic case with normal prion protein genotype. Acta Neuropathol 1997;93:317-22.

10 Gallassi R, Morreale A, Montagna P, et al. Fatal familial insomnia: behavioral and cognitive features. Neurology 1996:46:935-9.

11 Scaravilli F, Cordery RJ, Kretzschmar H, et al. Sporadic fatal insomnia: a case study. Ann Neurol 2000;48(4):665-8

12 Collinge J, Brown J, Hardy J, et al. Inherited prion disease with 144 base pair gene insertion. II: Clinical and pathological features. Brain 1992;115:687-710.

13 Snowden JS, Mann DMA, Neary D. Distinct neuropsychological characteristics in Creutzfeldt-Jakob disease. J Neurol Neurosurg Psychiatry 2002;73(6):686-94

14 Duffy P, Wolf J, Collins G, et al. Possible person-to-person transmission of Creutzfeldt-Jakob disease. N Engl J Med 1974;290:692-3.

15 Bernoulli C, Siegfried J, Baumgartner G, et al. Danger of accidental personto-person transmission of Creutzfeldt-Jakob disease by surgery [letter]. Lancet 1977;1:478-9.

16 Powell-Jackson J, Kennedy P, Whitcombe EM, et al. Creutzfeldt-Jakob disease and the administration of human growth hormone. Lancet 1985;ii:244-6.

17 Fradkin JE, Schonberger LB, Mills JL, et al. Creutzfeldt-Jakob disease in pituitary growth hormone recipients in the United States. JAMA 1991;265(7):880-4.

18 Cordery RJ, Hall M, Cipolotti L, et al. Early cognitive decline in CreutzfeldtJakob disease occurring in recipients of pituitary-derived human growth hormone. Abstract. Association of British Neurologists Autumn Meeting, September 2001

19 Alpers MP. Epidemiology and clinical aspects of Kuru. In: Prusiner SB, McKinley MP, eds. Prions: novel infectious pathogens causing scrapie and Creutzfeldt-Jakob disease. San Diego: Academic Press, 1987:451-65.

20 Bateman D, Hilton D, Love S, et al. Sporadic Creutzfeldt-Jakob disease in a 18-year-old in the UK. Lancet 1995;346:1155-6.

21 Tabrizi SJ, Scaravilli F, Howard RS, et al. Creutzfeldt-Jakob disease in a young woman. Lancet 1996;347:945-8.

22 Zeidler M, Stewart GE, Barraclough CR, et al. New variant Creutzfeldt-Jakob disease: neurological features and diagnostic tests. Lancet 1997;350:903-7.

23 Allroggen H, Dennis G, Abbott RJ, et al. New variant Creutzfeldt-Jakob disease: three case reports from Leicestershire. J Neurol Neurosurg Psychiatry 2000;68:375-8.

24 Spencer MD, Knight RSG, Will RG. First hundred cases of variant CreutzfeldtJakob disease: retrospective case note review of early psychiatric and neurological features. BMJ 2002;324:1479-82.

25 Kapur N, Ironside J, Abbott P, et al. A neuropsychological-neuropathological case study of variant Creutzfeldt-Jakob disease. Neurocase $2001 ; 7: 261-7$. 
26 Kapur N, Abbott P, Lowman A, et al. The neuropsychological profile associated with variant Creutzfeldt-Jakob disease. Brain 2003;126(12):2693-702.

27 Wechsler D. Manual for the Wechsler Adult Intelligence Scale-Revised. New York: Psychological Corporation, 1981.

28 Raven JC. Coloured progressive matrices. Oxford: Oxford Psychologists Press, 1976

29 Warrington EK. Recognition Memory Test. Windsor, UK: NFER-Nelson, 1984.

30 McKenna P, Warrington EK. The Graded Naming Test. Windsor, UK: NFERNelson, 1984

31 Oldfield RC, Wingfield A. Response latencies in naming objects. Q J Exp Psychol 1965;18:273-81.

32 Nelson H. The National Adult Reading Test (NART): test manual. Windsor, UK: NFER-Nelson, 1982.
33 Warrington EK, James M. The visual object and space perception battery Bury St Edmunds, UK: Thames Valley Test Company, 1991.

34 Nelson H. A modified sorting test sensitive to frontal lobe deficits. Cortex 1976;12:313-24.

35 Mcfie J, Piercy MF. The relation of laterality to performance on Weigl's test. $J$ Ment Sci 1952;98:299-305.

36 Ironside JW, Bell JE. Florid plaques and new variant Creutzfeldt-Jakob disease. Lancet 1997;350:1475.

37 Zeidler M, Sellar RJ, Collie DA, et al. The pulvinar sign on magnetic resonance imaging in variant Creutzfeldt-Jakob disease. Lancet 2000;355:1412-8.

38 Robinson DL, Cowie RJ. The primate pulvinar: structural, functional and behavioural components of visual salience. In: Steriade M, Jones EG, McCormick DA, eds. Thalamus. Vol II. Experimental and clinical aspects. Elsevier, 1997:53-92.

\section{Clinical Evidence - Call for contributors}

Clinical Evidence is a regularly updated evidence-based journal available worldwide both as a paper version and on the internet. Clinical Evidence needs to recruit a number of new contributors. Contributors are healthcare professionals or epidemiologists with experience in evidence-based medicine and the ability to write in a concise and structured way.

Areas for which we are currently seeking authors:

- Child health: nocturnal enuresis

- Eye disorders: bacterial conjunctivitis

- Male health: prostate cancer (metastatic)

- Women's health: pre-menstrual syndrome; pyelonephritis in non-pregnant women

However, we are always looking for others, so do not let this list discourage you.

Being a contributor involves:

- Selecting from a validated, screened search (performed by in-house Information Specialists) epidemiologically sound studies for inclusion.

- Documenting your decisions about which studies to include on an inclusion and exclusion form, which we keep on file.

- Writing the text to a highly structured template (about 1500-3000 words), using evidence from the final studies chosen, within 8-10 weeks of receiving the literature search.

- Working with Clinical Evidence editors to ensure that the final text meets epidemiological and style standards.

- Updating the text every six months using any new, sound evidence that becomes available. The Clinical Evidence in-house team will conduct the searches for contributors; your task is simply to filter out high quality studies and incorporate them in the existing text.

- To expand the topic to include a new question about once every 12-18 months.

If you would like to become a contributor for Clinical Evidence or require more information about what this involves please send your contact details and a copy of your CV, clearly stating the clinical area you are interested in, to Klara Brunnhuber (kbrunnhuber@ bmigroup.com).

\section{Call for peer reviewers}

Clinical Evidence also needs to recruit a number of new peer reviewers specifically with an interest in the clinical areas stated above, and also others related to general practice. Peer reviewers are healthcare professionals or epidemiologists with experience in evidence-based medicine. As a peer reviewer you would be asked for your views on the clinical relevance, validity, and accessibility of specific topics within the journal, and their usefulness to the intended audience (international generalists and healthcare professionals, possibly with limited statistical knowledge). Topics are usually 1500-3000 words in length and we would ask you to review between 2-5 topics per year. The peer review process takes place throughout the year, and our turnaround time for each review is ideally 10-14 days.

If you are interested in becoming a peer reviewer for Clinical Evidence, please complete the peer review questionnaire at www.clinicalevidence.com or contact Klara Brunnhuber (kbrunnhuber@bmigroup.com). 